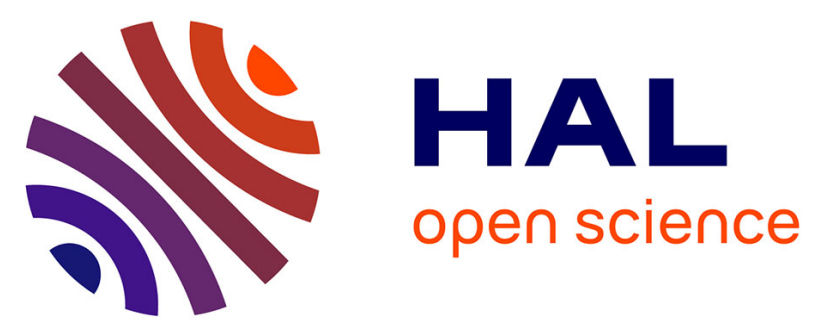

\title{
Labeled quantitative mass spectrometry to study the host response during aspergillosis in the common bottlenose dolphin (Tursiops truncatus)
}

Guillaume Desoubeaux, Maria del Carmen Piqueras, Carolina Le-Bert, Vanessa Fravel, Tonya Clauss, Alexa J Delaune, Risa Daniels, Eric D Jensen, Jennifer E Flower, Gregory D Bossart, et al.

\section{To cite this version:}

Guillaume Desoubeaux, Maria del Carmen Piqueras, Carolina Le-Bert, Vanessa Fravel, Tonya Clauss, et al.. Labeled quantitative mass spectrometry to study the host response during aspergillosis in the common bottlenose dolphin (Tursiops truncatus). Veterinary Microbiology, 2019, 232, pp.42-49. 10.1016/j.vetmic.2019.03.030 . hal-02439539

\section{HAL Id: hal-02439539 \\ https://hal.science/hal-02439539}

Submitted on 17 Jan 2020

HAL is a multi-disciplinary open access archive for the deposit and dissemination of scientific research documents, whether they are published or not. The documents may come from teaching and research institutions in France or abroad, or from public or private research centers.
L'archive ouverte pluridisciplinaire HAL, est destinée au dépôt et à la diffusion de documents scientifiques de niveau recherche, publiés ou non, émanant des établissements d'enseignement et de recherche français ou étrangers, des laboratoires publics ou privés. 
ORIGINAL RESEARCH PAPER

Labeled quantitative mass spectrometry to study the host response during aspergillosis in the common bottlenose dolphin (Tursiops truncatus)

Guillaume DESOUBEAUX ${ }^{1,2,3}$, Maria del Carmen PIQUERAS ${ }^{4}$, Carolina LE-BERT $^{5}$, Vanessa FRAVEL $^{6}$, Tonya CLAUSS ${ }^{7}$, Alexa J. DELAUNE ${ }^{7}$, Risa DANIELS $^{5}$, Eric D. JENSEN ${ }^{8}$, Jennifer E. FLOWER $^{9}$, Gregory D. BOSSART ${ }^{1,7}$, Sanjoy K. BHATTACHARYA ${ }^{4}$, and Carolyn CRAY ${ }^{1, *, \#}$

1. University of Miami, Division of Comparative Pathology, Department of Pathology \& Laboratory Medicine, Miller School of Medicine, Miami FL33136 - U.S.A.

2. CHU de Tours, Service de Parasitologie - Mycologie - Médecine tropicale, 37044 Tours - France

3. Université de Tours, CEPR - INSERM U1100 / Équipe 3, Faculté de Médecine, 37032 Tours - France

4. University of Miami, Bascom Palmer Eye Institute, Mass Spectrometry Core Facility, Miller School of Medicine, Miami FL33136 - U.S.A.

5. National Marine Mammal Foundation, San Diego CA 92106 - U.S.A.

6. Six Flags Discovery Kingdom, Vallejo CA 94589 - U.S.A.

7. Georgia Aquarium, Atlanta GA 30313 - U.S.A.

8. U.S. Navy Marine Mammal Program, San Diego CA 92152 - U.S.A.

9. Chicago Zoological Society’s Brookfield Zoo, Brookfield IL 60513 - U.S.A. current address: Mystic Aquarium, Mystic CT 06355 - U.S.A.

* Corresponding author: ccray@med.miami.edu; University of Miami, Division of Comparative Pathology, Department of Pathology \& Laboratory Medicine, Miller School of Medicine, Miami FL33136 - U.S.A., Phone: 3052436700

Short-running title: iTRAQ protocol for aspergillosis investigation

Figure count: 1

Table count: 2

Reference count: 33

Conflicts of interest: the authors have no conflicts of interest to declare

Word count: 3175 


\section{ABSTRACT}

Aspergillosis is a fungal infection caused by Aspergillus molds that can affect both humans and animals. Despite advances in diagnostics and therapy, medical management of this disease remains difficult. Expansion of the basic knowledge regarding its pathophysiology in animals is critical to aid in the identification of new biomarkers of infection for diagnosis and therapeutic targets. For such a purpose, proteomics can be used by addressing protein changes during various disease processes. In the present study, a mass spectrometry analysis based on isobaric tagging for relative and absolute quantitation $\left(\mathrm{iTRAQ}{ }^{\circledR}\right.$ ) was applied for direct identification and relative quantitation of proteins in blood collected from 32 Aspergillus-diseased common bottlenose dolphins (Tursiops truncatus, 32 samples) in comparison with blood from 55 other dolphins (55 samples from 41 clinically-normal controls and from 14 cetaceans with miscellaneous nonAspergillus inflammation diseases) and ten convalescent dolphins (28 samples). Sixty-six and 40 proteins were found to be $\geq 2.0$-fold over- and underrepresented versus miscellaneous nonAspergillus inflammatory dolphins, respectively, and most were confirmed vs. clinically-normal controls and convalescents. Many proteins which play a role in the adaptive immune response were identified, including MHC proteins and others involved in catalytic activity like the NADPH-ubiquinone oxido-reductases. Overall, iTRAQ ${ }^{\circledR}$ appears to be a convenient proteomic tool greatly suited for exploratory ex vivo studies focusing on pathophysiology. This technique should be considered as a preliminary step before validation of new diagnostic markers.

KEY WORDS: Aspergillosis; Dolphin; Interleukin; Orbitrap; Prepronociceptin; Protamine P1; Tursiops truncatus 


\section{INTRODUCTION}

Aspergillosis is an airborne fungal infection caused by saprophytic ubiquitous molds that belong to the Aspergillus genus (Latgé, 1999). It is responsible for several distinct respiratory diseases in both humans and animals. In marine mammals, Aspergillus-related disease is assumed to be rare, but it has been reported with increasing incidence: $66.7 \%$ of the 18 reported cases have been published after the year 2000 (Dagleish et al., 2008; Abdo et al., 2012). Aspergillosis can involve the lungs and brain in cetaceans (Latgé, 1999; Seyedmousavi et al., 2015). The major species responsible for infection belong to the Fumigati section (Lamoth, 2016), Nigri section and Terrei section in which A. fumigatus stricto sensu (ss), A. niger ss and A. terreus ss are the most frequently isolated (Balajee, 2009), respectively.

In marine mammals, and especially in dolphins, diagnostic tools are less developed than those for humans (Dagleish et al., 2008; Cassle et al., 2016). For instance, quantitative polymerase chain reaction (qPCR) has not been widely implemented in veterinary laboratories, and advanced medical imaging (computed tomography (CT), magnetic resonance imaging (MRI)) may not be accessible. Moreover, a positive culture from respiratory specimens does not definitively diagnose a true infection as it may reflect a simple colonization of the upper airways or represent an environmental contaminant (Desoubeaux et al., 2014). Also, as reported in humans, the sensitivity of blood cultures is very low for Aspergillus spp (Desoubeaux et al., 2014). Furthermore, detection of galactomannan antigen (GM) was demonstrated to be unreliable (Desoubeaux et al., 2017a). Conversely, serologic testing by western blot has been demonstrated to accurately detect anti-Aspergillus antibody in dolphin blood (Desoubeaux et al., 2017a). Thus, additional and novel biomarkers for aspergillosis should be investigated to improve the basic 
understanding of the pathophysiology of this disease. Evaluation of biomarkers in the host response may be able to provide such information.

Within the last decade, proteomics has been largely used for addressing significant protein changes within diseased organisms or pathologic fluids (Fekkar et al., 2012; Desoubeaux et al., 2013). Innovative mass spectrometry (MS) tools were initially developed for identification and qualitative characterization; however, some are now able to directly quantitate the relative amount of proteins identified. For instance, iTRAQ® (isobaric tags for relative and absolute quantitation) is an isobaric labeling method to identify and to determine the amount of proteins from different multiplexed sources within a single-run experiment (Ross et al., 2004;

Desoubeaux et al., 2017b). This technique uses stable isotope-tagged molecules that can be covalently bonded to the N-terminus and side chain amines of trypsin-digested peptides (Bourassa et al., 2015; Desoubeaux et al., 2018). In the present study, through an original MS approach based on $\mathrm{iTRAQ}{ }^{\circledR}$, we attempted to bring new insight to the host protein response against Aspergillus in diseased common bottlenose dolphins (Tursiops truncatus).

\section{MATERIAL AND METHODS}

\section{Animals}

Study population: inclusion and samples

Over 15 years, 115 blood samples were opportunistically collected during routine or clinical health assessments from 87 common bottlenose dolphins (Tursiops truncatus) under human care (from 2002 to 2016 (except for four samples obtained in 1991, 1993, 1993, and 1995), but 62.8\% obtained over the last three years). The cetaceans were hosted in several different facilities 
throughout the United States of America (U.S.A.). All blood samples were centrifuged and plasma specimens were stored at $-20^{\circ} \mathrm{C}$ or $-80^{\circ} \mathrm{C}$ prior to being utilized for MS.

No dolphins were anesthetized or euthanized for the purposes of this study. This study was conducted using archived samples collected from Six Flags Aquarium, Georgia Aquarium, Chicago Zoological Society (CZS), and US Navy marine mammals as part of their routine care. The US Navy Marine Mammal Program (MMP) houses and cares for a population of dolphins in San Diego Bay (CA, USA). The MMP is Association for Assessment and Accreditation of Laboratory Animal Care (AAALAC)-accredited and adheres to the national standards of the United States Public Health Service on the Human Care and Use of Laboratory Animals and the Animal Welfare Act. Georgia Aquarium and CZS are USDA/APHIS approved and inspected facilities and members of the Association of Zoos and Aquariums and the Alliance of Marine Mammal Parks and Aquariums. Both have been awarded the Humane Conservation certification by American Humane. Biological samples for this study were taken as a part of a preventative medicine program or for medical monitoring purposes.

\section{Case definitions}

Aspergillosis classification in dolphins was derived from the definition utilized in human medicine (De Pauw et al., 2008; Arendrup et al., 2012; Marchetti et al., 2012). For example, the definitive diagnosis of "proven" aspergillosis was based upon histopathologic evidence (Desoubeaux et al., 2014). The diagnosis of "probable" aspergillosis was based upon positive mycological culture in conjunction with clinical examination, imaging investigations, and any clinical signs which could corroborate the diagnosis. Since GM detection was shown to be unreliable in cetaceans, it was not considered to be a pivotal parameter for the diagnosis of 
"probable" infection (Desoubeaux et al., 2017a). Notably, samples obtained from dolphins with clinical signs consistent with possible aspergillosis, but with no positive mycological cultures, were excluded from the subsequent analysis, unless they had significant anti-Aspergillus antibody titers, i.e. equal or superior to 1: 512 ELISA titers (Desoubeaux et al., 2017a). Altogether, 32 dolphins $\left(n_{1}\right)$ were included in the Aspergillus-diseased group. An additional category, referred to as convalescent, was defined for that recovered from aspergillosis, i.e. sampling date greater than three months after the diagnosis, if clinical improvement was noticed and/or long-term antifungal therapy was given. Thus, twenty-eight samples were obtained from ten of the $n_{1}$ aforementioned cetaceans. In average, convalescent dolphins were tested $2.8 \pm 1.6$ times, $47.7 \pm 40.8$ months after the initial diagnosis of aspergillosis.

Animals with no apparent clinical signs were considered as healthy controls and classified into the clinically-normal group $\left(n_{2},=41\right)$, while those undergoing miscellaneous non-Aspergillus inflammatory processes were classified as non-Aspergillus inflammatory dolphins $\left(n_{2},=14\right)$.

\section{Proteomic analysis}

Pre-processing step with iTRAQ $Q^{\circledR}$-tags labeling

This protocol was the same as described previously (Desoubeaux et al., 2018). Briefly, protein enrichment was completed using the Pierce Albumin / IgG removal ${ }^{\circledR}$ kit (ThermoFisher Scientific, Waltham, MA, U.S.A.) that allows for depletion of overrepresented proteins like albumin or immunoglobulins (Kumar et al., 2012). Total protein content was quantified by the Pierce BCA Protein assay ${ }^{\circledR}$ kit (ThermoFisher Scientific, Waltham, MA, U.S.A.), according to the manufacturer's instructions (Kumar et al., 2012; Desoubeaux et al., 2013). All depleted blood 
samples were thereafter pooled, on the basis of $1,000 \mu \mathrm{g}$ protein for each, in four distinct aliquots, according to the clinical group the dolphins were affiliated with: clinically-normal controls, non-Aspergillus inflammatory dolphins, Aspergillus-diseased animals, and convalescent subjects. Then, $100 \mu \mathrm{g}$ of every pool was incubated with $30 \mu \mathrm{L}$ dissolution buffer of $0.5 \mathrm{M}$ triethylammonium bicarbonate (Sigma-Aldrich, Saint-Louis, MO, U.S.A.) at pH 8.5, and thereafter treated with $2.0 \%$ SDS-denaturant solution. One microliter of tris-(2carboxyethyl)phosphine-reducing reagent was added, followed by vortex-shaking for 1 min, centrifugation at $18,000 \mathrm{x} g$ for $5 \mathrm{~min}$ and incubation at $60^{\circ} \mathrm{C}$ for $1 \mathrm{~h}$. After another step of shaking and centrifugation, $84 \mathrm{mM}$ iodoacetamide was added for a 30 min-long incubation in the dark at room temperature. Freshly prepared $0.1 \mu \mathrm{g} / \mu \mathrm{L}$ sequencing grade modified trypsin was then mixed with each sample, and digestion was carried out at $37^{\circ} \mathrm{C}$ during $30 \mathrm{~min}$. Thereafter, $1 \mu \mathrm{L}$ trypsin was added to continue digestion overnight. The samples were dried in an Eppendorf Vacufuge $^{\circledR}$ concentrator, and then reconstituted with $30 \mu \mathrm{L}$ dissolution buffer. Every tube was mixed with one unique iTRAQ ${ }^{\circledR}$ reagent (Sigma-Aldrich, Saint-Louis, MO, U.S.A.) and reconstituted in isopropanol, according to the manufacturer's recommendations. The tube containing all the blood samples pooled from clinically-normal controls was mixed with the 117reagent, those from miscellaneous non-Aspergillus inflammatory dolphins with the 118-reagent, those from Aspergillus-diseased dolphins with the 119-reagent, and those from Aspergillusconvalescent dolphins with the 121-reagent. Thereafter, the contents of all these iTRAQ ${ }^{\circledR}$ reagents-labelled tubes were combined into one single tube, vortexed for $1 \mathrm{~min}$, and centrifuged at $18,000 \mathrm{~g}$ for $5 \mathrm{~min}$. The multiplexed specimen was thoroughly dried by centrifugal vacuum concentration as above. 
Processing steps by mass spectrometry

The multiplexed iTRAQ ${ }^{\circledR}$ specimen was re-suspended in $2.0 \%$ acetonitrile and loaded onto a high performance liquid chromatographic (HPLC) instrument. HPLC analysis was conducted in an Easy Nano LC $1000^{\circledR}$ model (ThermoFisher Scientific, Waltham, MA, U.S.A.) where a $75 \mu \mathrm{m}$ i.d. x $15 \mathrm{~cm}$ column, packed with Acclaim PepMap ${ }^{\circledR}$ RSLC C18-2 $\mu \mathrm{m} 100$ Å column (ThermoFisher Scientific, Waltham, MA, U.S.A.), was in-line connected to a Acclaim PepMap ${ }^{\circledR}$ 10075 um x 2 cm, nanoviper C18-3 um $100 \AA ̊$ A pre-column (ThermoFisher Scientific, Waltham, MA, U.S.A.). Peptides were eluted following a 75 min gradient from $2.0 \%$ to $98.0 \%$ acetonitrile (ThermoFisher Scientific, Waltham, MA, U.S.A.) with a water flow of $350 \mathrm{~nL} / \mathrm{min}$ into a QExactive ${ }^{\circledR}$ Orbitrap mass spectrometer (ThermoFisher Scientific, Pittsburg, PA, U.S.A.) in data-dependent mode, with an automatic gain control (AFC) target of $1.0 \times 10^{6}$ for full MS at 70,000 resolution, and of $2.0 \times 10^{5}$ for dd-MS ${ }^{2}$ at 17,500 resolution in positive mode. The isolation window was fixed to $1.5 \mathrm{~m} / \mathrm{z}$ with normalized collision energy of $28 \mathrm{eV}$, underfill ratio of $1.0 \%$, and dynamic exclusion of 3.0. First mass was fixed to $103 \mathrm{~m} / \mathrm{z}$. QExactive ${ }^{\circledR}$ Orbitrap typical technical specifications are evaluated as follows: high resolving power of 140,000 full width at half maximum, defined at $\mathrm{m} / \mathrm{z} 200$, and elevated resolution at $\Delta_{m / z}=0.001$, with a $50-4,000 \mathrm{~m} / \mathrm{z}$ range (Holčapek et al., 2012).

Mass spectrometry data analysis and identification/quantitation of host proteins

The bioinformatics analysis was performed using Proteome Discoverer ${ }^{\circledR}$ software (ThermoFisher Scientific, Pittsburg, PA, U.S.A.). Specific SwissProt ${ }^{\circledR}$ reviewed non-redundant databases (http://www.uniprot.org/uniprot/) were used for the analysis of dolphin or dolphin-like 
(according to the following genera: Tursiops, Cephalorhynchus, Grampus, Lagenorhynchus, Platanista, Sotalia, Stenella, Inia, Lipotes, and Sousa) proteome using Sequest ${ }^{\circledR}$ HT search engine (Washington DC, U.S.A.). The parameters of the study set trypsin as the enzyme used for digestion, with a maximum number of missed cleavage sites of two, $10 \mathrm{ppm}$ as precursor mass tolerance, and 0.02 Da for fragment mass tolerance. Alkylation, as well as $\mathrm{N}$-terminal / lysine modifications and dynamic iTRAQ ${ }^{\circledR}$ modifications were selected as fixed. Maximum value for delta correlation was set to 0.05 . False discovery rate target value was 0.01 for strict rate and 0.05 for relaxed one, considering the $q$-value as a validation reference. At the quantification level, the analysis included K-means clustering, i.e. supervised and heuristic algorithm, for both protein and peptide quantitation ratios. The software actually worked by grouping proteins, based on the peptide spectral match (PSMs). Then, a customized ratio was calculated for every protein group as the median of all PSMs included in the protein group.

\section{Statistical analysis}

Statistical analyses were performed using XLStat ${ }^{\circledR}$ v.2016.6.04 software (Addinsoft, Paris, France). Missing data, e.g. when the total volume of sample was insufficient to complete all the analyses, were managed by the method of mean imputation. The $\alpha$-risk was adjusted at 0.05 .

Regarding specifically the iTRAQ® data, we based inference on one-way analysis of variance (ANOVA) models, with the data analysis conducted one protein at a time (Unwin et al., 2005; Keshamouni et al., 2006), combining both normalization, i.e. bias removal, and assessment of differential protein expression in a single model fit to the collection of reporter ion peak areas, i.e. corrected for isotopic overlap, from all observed tandem mass spectra. Significant cutoff for 
determination of over- or underrepresentation was set at $\geq 2$-fold in comparison of the Aspergillus-diseased cases with the other three groups (Desoubeaux et al., 2018). Principal component analysis (PCA) was used to facilitate interpretation of the multivariate proteome dynamics dataset (Rao and Li, 2009). Data were z-scored prior to model building.

\section{RESULTS}

\section{Study population and samples}

Characteristics of included dolphins are detailed in Table 1. Measurement of GM antigen in blood was not diagnostic, displaying the following mean values: $0.2 \pm 0.1$ versus $0.2 \pm 0.2$ $\mathrm{ng} / \mathrm{mL}$ for Aspergillus-diseased cases and controls. There was a significant difference between anti-Aspergillus antibody titers in diseased and control dolphins $(\mathrm{p}<0.0001)$.

\section{Proteomic analysis}

Overall, MS analysis achieved identification of 1,385 proteins in dolphin blood. Sixty-six proteins were statistically overexpressed in Aspergillus-diseased dolphins vs. miscellaneous nonAspergillus inflammatory dolphins (Figure 1), i.e. 2.0\% of the whole dolphin (Tursiops truncatus) proteome, and 52 / 66 (78.8\%) were also overrepresented as compared to clinicallynormal dolphins. Out of the 66 proteins overrepresented, 48 / 66 (72.7\%) were also in overabundance $v s$. clinically-normal controls, and $46.15 \%$ were located at the cell membrane and 19.2\% in the extracellular compartment. Fifty percent represented binding activity, whereas 
$35.7 \%$ and $25.0 \%$ were involved in catalytic processes and signal transduction (Figure 1).

Thirteen (13 / 66; 19.7\%) were dramatically increased ( $\geq 4.0$-fold) when compared to miscellaneous non-Aspergillus inflammatory dolphins (Table 2), primarily potassium inwardlyrectifying channel J1-like protein. There was a major presence of proteins belonging to the major histocompatibility complex (MHC): major histocompatibility complex class II beta chain and MHC class I antigen, increased by $>100.00$-fold and 4.48-fold. Similarly, some nicotinamide adenine dinucleotide phosphate- (NADPH-) ubiquinone oxido-reductases were also increased with Aspergillus infection. Except for NADH-ubiquinone oxidoreductase chain 5 and endothelin1 receptor, all of these 13 markedly-increased proteins returned to normal levels during the convalescent period.

Forty proteins were underrepresented in Aspergillus-diseased dolphins vs. miscellaneous nonAspergillus inflammatory dolphins (Figure 1), which represents $1.1 \%$ of the dolphin proteome, and 31 / $40(77.5 \%)$ were confirmed to be lower when compared to clinically-normal controls. Among these 40 proteins, $47.4 \%$ were located at the membrane cell, and $31.6 \%$ in the mitochondrion. Fifty-six percent, $36.0 \%$ and $28.0 \%$ expressed catalytic, binding and transport activities, respectively (Figure 1). Six proteins / $40(15.0 \%)$ were reduced by $\geq 4.0$-fold in Aspergillus-diseased dolphins vs. miscellaneous non-Aspergillus inflammatory dolphins: retinoblastoma binding protein 8 , prepronociceptin, extra-spindle poles-like protein $1, \mathrm{NADH}$ dehydrogenase subunit 2, interleukin 4 (IL-4), and NADH-ubiquinone oxidoreductase chain 2. The last four were also decreased in convalescent dolphins.

\section{DISCUSSION}


In marine mammals, development of aspergillosis varies fundamentally in comparison to the infection in humans. For instance, in dolphins, it appears to be associated with a chronic invasive process; generally suggestive of another disease and/or (sub-)acute physiologic stress (Desoubeaux et al., 2017a) rather than associated with severe immunosuppression and profound neutropenia as observed in humans (Seyedmousavi et al., 2015). Underlying pulmonary disease may affect host defense mechanisms, leading to long-term colonization in dolphin lungs and potential invasion of bronchial tissue by Aspergillus spp (Reidarson et al., 1998). Other organs, including the brain, may also be infected following systemic dissemination (Dagleish et al., 2008; Abdo et al., 2012). Thus, as observed in this study, the diagnosis of aspergillosis is particularly challenging in dolphins (Seyedmousavi et al., 2015; Desoubeaux et al., 2017a). For example, GM antigen is not contributive and true positive mycological cultures are infrequent; there is a common observation of colonization or chronic infection compared to humans. Therefore, it is critical to describe new biomarkers of aspergillosis to aid diagnosis and prognosis, to suggest alternative therapeutic targets, and to decrease the related morbidity and mortality in dolphins.

Through its sensitivity and by comprehensively addressing the pathophysiology, proteomics may contribute to the discovery of new markers and their clinical validation in diseased animals (Desoubeaux et al., 2013). In such a context, iTRAQ ${ }^{\circledR}$ appears to be an accurate and innovative technique based on an affordable ready-to-use kit (Kumar et al., 2012; Bourassa et al., 2015; Desoubeaux et al., 2017b, 2018), provided there is availability of a performant MS instrument. For this reason, we had to circumvent several technical limitations. First, we included relevant controls for reliable comparison: we rigorously enforced recruitment of samples from dolphins which experienced various inflammatory diseases, including other fungal infections like 
mucormycosis and histoplasmosis. Second, to reduce disease misclassification, we used a composite criterion based on clinical data, histopathology, and mycological culture as it is consensually approved for disease classification in human infections (Desoubeaux et al., 2014). Lastly, given the probability of homologous proteins, we decided to consult broad SwissProt ${ }^{\circledR}$ databases. The latter voluntarily encompassed ten dolphin and dolphin-like genera in order to allow identification of more proteins when compared to browsing the database restricted to Tursiops truncatus species. Unfortunately, it was not possible to analyze protein enrichment according to the Gene Ontogeny (GO) (http://www.geneontology.org/) (Desoubeaux et al., 2018), because all the current classification system, including PANTHER classification systems version 13.1 (released 2018-02-03) (Mi et al., 2017), are lacking data related to cetaceans. This highlights the critical need to increase current databases that poorly represent marginal micro- or macro-organisms.

Our MS study described significant qualitative and quantitative changes in the dolphin blood proteome. This protein spectrum brought new insight into the host defense mechanisms and showed major involvement of proteins with binding and catalytic functions as previously observed with rats and penguins (Desoubeaux et al., 2018). A major moiety was expressed in the extracellular compartment or at the cell membrane which suggests that these proteins are massively discarded into circulation during Aspergillus infection. The major representation of proteins related to $\mathrm{MHC}$ underscores the role of adaptive immunity during aspergillosis in dolphins (Beineke et al., 2010). This also reemphasizes how anti-infectious responses vary based on the host: for instance in humans, adaptive immunity plays a minor role against Aspergillus infection, while polymorphonuclear neutrophils and macrophages are primarily recruited 
(Dagenais and Keller, 2009). We made similar observations in a neutropenic rat model (Chandenier et al., 2009; Desoubeaux et al., 2018).

Several NADPH-ubiquinone oxido-reductase proteins and cytochrome $b$ were described as overrepresented in the current study. They are believed to be required for catalysis which functions in the transfer of electrons to the respiratory chain required for enzymatic activity to fight against aspergillosis. IL-4 was found largely decreased in our study. In other studies, IL-4deficient mice developed attenuated airway inflammation compared with wild-type rodents (Choi and Reiser, 1998), and we also observed increased protein expression related to the interleukin signaling pathway in our acute rat model of aspergillosis (Desoubeaux et al., 2018). Similarly, prepronociceptin concentration was moderately lower in Aspergillus-diseased dolphins $v s$. non-Aspergillus inflammatory animals, which is consistent with previous findings showing significant increase in systemic chronic inflammation models (Liu et al., 2012). In the dolphin, decreased prepronociceptin concentration can be hypothesized as a physiological adaptation to chronic infection caused by Aspergillus. As up-regulation of the prepronociceptin system was previously demonstrated to alter airway hyper-responsiveness (Singh et al., 2013), down-regulation can be assumed to play an opposite role in modulating airway inflammation and airway tone. Interestingly, bacterial infections were demonstrated to have significant negative impact on protamine P1 concentration (Zeyad et al., 2018) whereas Aspergillus-infection appeared to induce positive effects in dolphins, by increasing it more than 15 -fold. This finding may suggest a potential clue for differential diagnosis between bacterial and fungal infections. Other studies have shown significant antimicrobial activity of protamine (Kim et al., 2015).

Overall, the present study highlighted the potential of MS analysis for characterizing the pathophysiology of aspergillosis. Use of the $\mathrm{iTRAQ}^{\circledR}$ protocol provided new insight on the host 
inflammatory response against Aspergillus in naturally-infected mammals. This study may serve as a reliable preliminary trial towards the discovery of new biomarkers of infection and the suggestion of therapeutic targets. Further studies are warranted to validate these results and expand upon the construction of functional protein networks in aspergillosis. The example of iTRAQ $^{\circledR}$ protocol application for aspergillosis in dolphins should be easily reproducible for other diseases and in various host species.

\section{ACKNOWLEDGMENTS}

The authors thank all the veterinarians and practitioners that enrolled their animal patients. They are grateful to all the multi-institutional animal care and biological staff dedicated to the care and monitoring of the bottlenose dolphins in this study.

\section{FUNDING}

This work was supported by internal laboratory funding and partly by NIH center grant P30EY14801. There is no disclosure of conflict of interest.

\section{LITERATURE CITED}

Abdo, W., Kawachi, T., Sakai, H., Fukushi, H., Kano, R., Shibahara, T., Shirouzu, H., Kakizoe, Y., Tuji, H., Yanai, T., 2012. Disseminated mycosis in a killer whale (Orcinus orca). J. Vet. Diagn. Investig. Off. Publ. Am. Assoc. Vet. Lab. Diagn. Inc 24, 211-218. doi: $10.1177 / 1040638711416969$

Arendrup, M.C., Bille, J., Dannaoui, E., Ruhnke, M., Heussel, C.-P., Kibbler, C., 2012. ECIL-3 classical diagnostic procedures for the diagnosis of invasive fungal diseases in patients with leukaemia. Bone Marrow Transplant. 47, 1030-1045. doi:10.1038/bmt.2011.246 
Balajee, S.A., 2009. Aspergillus terreus complex. Med. Mycol. 47 Suppl 1, S42-46. doi:10.1080/13693780802562092

Beineke, A., Siebert, U., Wohlsein, P., Baumgärtner, W., 2010. Immunology of whales and dolphins. Vet. Immunol. Immunopathol. 133, 81-94. doi:10.1016/j.vetimm.2009.06.019

Bourassa, S., Fournier, F., Nehmé, B., Kelly, I., Tremblay, A., Lemelin, V., Lamarche, B., Couture, P., Droit, A., 2015. Evaluation of iTRAQ and SWATH-MS for the quantification of proteins associated with insulin resistance in human duodenal biopsy samples. PloS One 10, e0125934. doi:10.1371/journal.pone.0125934

Cassle, S.E., Landrau-Giovannetti, N., Farina, L.L., Leone, A., Wellehan, J.F.X., Stacy, N.I., Thompson, P., Herring, H., Mase-Guthrie, B., Blas-Machado, U., Saliki, J.T., Walsh, M.T., Waltzek, T.B., 2016. Coinfection by cetacean morbillivirus and Aspergillus fumigatus in a juvenile bottlenose dolphin (Tursiops truncatus) in the Gulf of Mexico. J. Vet. Diagn. Investig. Off. Publ. Am. Assoc. Vet. Lab. Diagn. Inc 28, 729-734. doi:10.1177/1040638716664761

Chandenier, J., Bernard, S., Montharu, J., Bailly, E., Fetissof, F., de Monte, M., Desoubeaux, G., Diot, P., Richard-Lenoble, D., 2009. The utility of a nebulised intra-tracheal rat model of invasive pulmonary aspergillosis. Mycoses 52, 239-245. doi:10.1111/j.14390507.2009.01695.x

Choi, P., Reiser, H., 1998. IL-4: role in disease and regulation of production. Clin. Exp. Immunol. 113, 317-319. doi:10.1046/j.1365-2249.1998.00690.x

Dagenais, T.R.T., Keller, N.P., 2009. Pathogenesis of Aspergillus fumigatus in invasive aspergillosis. Clin. Microbiol. Rev. 22, 447-465. doi:10.1128/CMR.00055-08

Dagleish, M.P., Foster, G., Howie, F.E., Reid, R.J., Barley, J., 2008. Fatal mycotic encephalitis caused by Aspergillus fumigatus in a northern bottlenose whale (Hyperoodon ampullatus). Vet. Rec. 163, 602-604.

De Pauw, B., Walsh, T.J., Donnelly, J.P., Stevens, D.A., Edwards, J.E., Calandra, T., Pappas, P.G., Maertens, J., Lortholary, O., Kauffman, C.A., Denning, D.W., Patterson, T.F., Maschmeyer, G., Bille, J., Dismukes, W.E., Herbrecht, R., Hope, W.W., Kibbler, C.C., Kullberg, B.J., Marr, K.A., Muñoz, P., Odds, F.C., Perfect, J.R., Restrepo, A., Ruhnke, M., Segal, B.H., Sobel, J.D., Sorrell, T.C., Viscoli, C., Wingard, J.R., Zaoutis, T., Bennett, J.E., European Organization for Research and Treatment of Cancer/Invasive Fungal Infections Cooperative Group, National Institute of Allergy and Infectious Diseases Mycoses Study Group (EORTC/MSG) Consensus Group, 2008. Revised definitions of invasive fungal disease from the European Organization for Research and Treatment of Cancer/Invasive Fungal Infections Cooperative Group and the National Institute of Allergy and Infectious Diseases Mycoses Study Group (EORTC/MSG) consensus group. Clin. Infect. Dis. Off. Publ. Infect. Dis. Soc. Am. 46, 1813-1821. doi: $10.1086 / 588660$

Desoubeaux, G., Bailly, É., Chandenier, J., 2014. Diagnosis of invasive pulmonary aspergillosis: updates and recommendations. Med. Mal. Infect. 44, 89-101.

doi:10.1016/j.medmal.2013.11.006

Desoubeaux, G., Chauvin, D., Piqueras, M.D.C., Bronson, E., Bhattacharya, S.K., Sirpenski, G., Bailly, E., Cray, C., 2018. Translational proteomic study to address host protein changes during aspergillosis. PloS One 13, e0200843. doi:10.1371/journal.pone.0200843

Desoubeaux, G., Jourdan, M.-L., Valera, L., Jardin, B., Hem, S., Caille, A., Cormier, B., Marchand-Adam, S., Bailly, E., Diot, P., Chandenier, J., 2013. Proteomic demonstration 
of the recurrent presence of inter-alpha-inhibitor $\mathrm{H} 4$ heavy-chain during aspergillosis induced in an animal model. Int. J. Med. Microbiol. IJMM.

Desoubeaux, G., Le-Bert, C., Fravel, V., Clauss, T., Delaune, A.J., Soto, J., Jensen, E.D., Flower, J.E., Wells, R., Bossart, G.D., Cray, C., 2017a. Evaluation of a genus-specific ELISA and a commercial Aspergillus Western blot IgG® immunoblot kit for the diagnosis of aspergillosis in common bottlenose dolphins (Tursiops truncatus). Med. Mycol. doi:10.1093/mmy/myx 114

Desoubeaux, G., Piqueras, M.D.C., Pantin, A., Bhattacharya, S.K., Peschke, R., Joachim, A., Cray, C., 2017b. Application of mass spectrometry to elucidate the pathophysiology of Encephalitozoon cuniculi infection in rabbits. PloS One 12, e0177961. doi:10.1371/journal.pone.0177961

Fekkar, A., Pionneau, C., Brossas, J.Y., Marinach-Patrice, C., Snounou, G., Brock, M., IbrahimGranet, O., Mazier, D., 2012. DIGE enables the detection of a putative serum biomarker of fungal origin in a mouse model of invasive aspergillosis. J. Proteomics 75, 2536-2549. doi:10.1016/j.jprot.2012.01.040

Holčapek, M., Jirásko, R., Lísa, M., 2012. Recent developments in liquid chromatography-mass spectrometry and related techniques. J. Chromatogr. A 1259, 3-15. doi:10.1016/j.chroma.2012.08.072

Keshamouni, V.G., Michailidis, G., Grasso, C.S., Anthwal, S., Strahler, J.R., Walker, A., Arenberg, D.A., Reddy, R.C., Akulapalli, S., Thannickal, V.J., Standiford, T.J., Andrews, P.C., Omenn, G.S., 2006. Differential protein expression profiling by iTRAQ-2DLCMS/MS of lung cancer cells undergoing epithelial-mesenchymal transition reveals a migratory/invasive phenotype. J. Proteome Res. 5, 1143-1154. doi:10.1021/pr050455t

Kim, Y.-H., Kim, S.M., Lee, S.Y., 2015. Antimicrobial activity of protamine against oral microorganisms. Biocontrol Sci. 20, 275-280. doi:10.4265/bio.20.275

Kumar, Y., Liang, C., Bo, Z., Rajapakse, J.C., Ooi, E.E., Tannenbaum, S.R., 2012. Serum proteome and cytokine analysis in a longitudinal cohort of adults with primary dengue infection reveals predictive markers of DHF. PLoS Negl. Trop. Dis. 6, e1887. doi:10.1371/journal.pntd.0001887

Lamoth, F., 2016. Aspergillus fumigatus-related species in clinical practice. Front. Microbiol. 7, 683. doi:10.3389/fmicb.2016.00683

Latgé, J.P., 1999. Aspergillus fumigatus and aspergillosis. Clin. Microbiol. Rev. 12, 310-350.

Liu, E.H., Li, C., Govindasamy, M., Neo, H.J., Lee, T.L., Low, C.M., Tachibana, S., 2012. Elevated prepronociceptin, nociceptin/orphanin FQ and nocistatin concentrations in rat chronic constriction nerve injury and diabetic neuropathic pain models. Neurosci. Lett. 506, 104-106. doi:10.1016/j.neulet.2011.10.059

Marchetti, O., Lamoth, F., Mikulska, M., Viscoli, C., Verweij, P., Bretagne, S., European Conference on Infections in Leukemia (ECIL) Laboratory Working Groups, 2012. ECIL recommendations for the use of biological markers for the diagnosis of invasive fungal diseases in leukemic patients and hematopoietic SCT recipients. Bone Marrow Transplant. 47, 846-854. doi:10.1038/bmt.2011.178

Mi, H., Huang, X., Muruganujan, A., Tang, H., Mills, C., Kang, D., Thomas, P.D., 2017. PANTHER version 11: expanded annotation data from Gene Ontology and Reactome pathways, and data analysis tool enhancements. Nucleic Acids Res. 45, D183-D189. doi:10.1093/nar/gkw 1138 
Rao, P.K., Li, Q., 2009. Principal component analysis of proteome dynamics in iron-starved Mycobacterium tuberculosis. J. Proteomics Bioinform. 2, 19-31.

Reidarson, T.H., Harrell, J.H., Rinaldi, M.G., McBain, J., 1998. Bronchoscopic and serologic diagnosis of Aspergillus fumigatus pulmonary infection in a bottlenose dolphin (Tursiops truncatus). J. Zoo Wildl. Med. Off. Publ. Am. Assoc. Zoo Vet. 29, 451-455.

Ross, P.L., Huang, Y.N., Marchese, J.N., Williamson, B., Parker, K., Hattan, S., Khainovski, N., Pillai, S., Dey, S., Daniels, S., Purkayastha, S., Juhasz, P., Martin, S., Bartlet-Jones, M., He, F., Jacobson, A., Pappin, D.J., 2004. Multiplexed protein quantitation in Saccharomyces cerevisiae using amine-reactive isobaric tagging reagents. Mol. Cell. Proteomics MCP 3, 1154-1169. doi:10.1074/mcp.M400129-MCP200

Seyedmousavi, S., Guillot, J., Arné, P., de Hoog, G.S., Mouton, J.W., Melchers, W.J.G., Verweij, P.E., 2015. Aspergillus and aspergilloses in wild and domestic animals: a global health concern with parallels to human disease. Med. Mycol. 53, 765-797. doi:10.1093/mmy/myv067

Singh, S.R., Sullo, N., D’Agostino, B., Brightling, C.E., Lambert, D.G., 2013. The effects of nociceptin peptide (N/OFQ)-receptor (NOP) system activation in the airways. Peptides 39, 36-46. doi:10.1016/j.peptides.2012.10.008

Unwin, R.D., Pierce, A., Watson, R.B., Sternberg, D.W., Whetton, A.D., 2005. Quantitative proteomic analysis using isobaric protein tags enables rapid comparison of changes in transcript and protein levels in transformed cells. Mol. Cell. Proteomics MCP 4, 924935. doi:10.1074/mcp.M400193-MCP200

Zeyad, A., Hamad, M.F., Hammadeh, M.E., 2018. The effects of bacterial infection on human sperm nuclear protamine P1/P2 ratio and DNA integrity. Andrologia 50. doi:10.1111/and.12841

\section{FIGURE LEGEND}

Figure 1: Global protein changes in Aspergillus-diseased common bottlenose dolphins

(Tursiops truncatus) versus non-Aspergillus inflammatory animals. In the upper panel, the bar graph indicates the absolute number of proteins that were found positively or negatively $\geq 2.0$ fold differentially-expressed. The extreme upper and lower parts of the bars (no hatching) represent the protein moiety $\geq 4.0$-fold differentially-expressed. In the middle panel, the pie charts display the distribution of the subcellular locations for each differentially-expressed protein. In the lower panel, the bar graph shows the molecular functions of these proteins. 